\title{
Lysozyme Secreting Tumor: A Case of Gastric Cancer Associated with Myelofibrosis due to Disseminated Bone Marrow Metastatasis
}

\author{
Tohru Takahashi, Tetsuo Akihama, Akihiko Yamaguchi, Kosaku Yoshida, \\ Akira B. Miura, Yoshitaka Uesaka* and Tomoo Tsuburaya
}

\begin{abstract}
One patient with gastric carcinoma and secondary myelofibrosis due to disseminated bone marrow metastasis had markedly elevated lysozyme (LZM) levels in serum and urine with the intense presence of LZM within tumor tissues. It is considered to be a case of gastric carcinoma with LZM secreting functional capacities. To date, there were many reported cases to verify the LZM positive cells by LZM staining in the tissue of gastric carcinoma and to demonstrate the elevated serum levels of LZM in malignant tumor bearing patients, whereas no papers to disclose the elevated levels of LZM in serum and urine originated from the productions and secretions of gastric carcinoma cells. So, this report might be the first reported case of LZM secreting tumor verified by LZM staining of carcinoma cells except for haematological malignancies such as acute monocy tic leukemia or myelomonocytic leukemia.
\end{abstract}

Key Words: $\quad$ Lysozyme, Gastric carcinoma, Secondary myelofibrosis.

Lysozyme (LZM), also known by the synonym "Muramidase", is an hydrolytic enzyme which acts through the dissolution of $\mathrm{N}$-acetylglucosamyl-N-acetylmuramic acid linkages in the cell wall of succeptible microorganisms, especially gram positive cocci. There is also evidence that LZM has anaerobic antibacterial action in tissue secretions. In normal subjects, LZM is abundant in monocyte-macrophages and mature granulocytes and is physiologically distributed in tears, saliva, nasal secretions, human milk, hyaline cartilages, kidney (renal tubular cells) and paneth cells. ${ }^{1,2)}$

LZM is considered to be one of many markers of monocyte-macrophage series and contributes to nonspecific host defense system against exogenous microorganisms. ${ }^{3}$ )

Furthermore, markedly elevated LZM levels in serum and urine are often found in cases of acute monocytic leukemia (AMoL), myelomonocytic leukemia (AMMoL) ${ }^{4)}$ and sometimes acute myelocytic leukemia (AML), chronic myelocytic leukemia (CML), erythroleukemia (EL) and other myeloproliferative disorders. ${ }^{5-9)}$ In those cases, measurements of LZM levels in serum and urine may aid of making a diagnosis and evaluating clinical course and prognosis more evidently.

But until now, there are not any reported cases which showed elevated LZM levels in serum and urine with the presence of LZM within tumor tissues except for the above mentioned leukemia cells. $^{10,11)}$

\section{CASE REPORT}

A 57-year-old male was admitted to our clinic on 20th November, 1979, because of lumbago, weightloss and general lassitude.The patient had a history of hospitalization for 3 months in 1967 because of traumatic cervical syndrome and compression fracture of the VIIth thoracic vertebra. Three months before admission, the patient noticed dorsolumbar pain and weightloss so then consulted a physician, by whom the presence of severe anemia was pointed out. Thereafter anemia

From the Third Department of Internal Medicine and

*the First Department of Pathology, Akita University School of Medicine.

Received for publication September 25, 1983.

Reprint request to: Tohru Takahashi, MD. The Third Department of Internal Medicine, Akita University School of Medicine, 1-1-1 Hondo, Akita 010, Japan. 
Table 1. Laboratory Findings on Admission

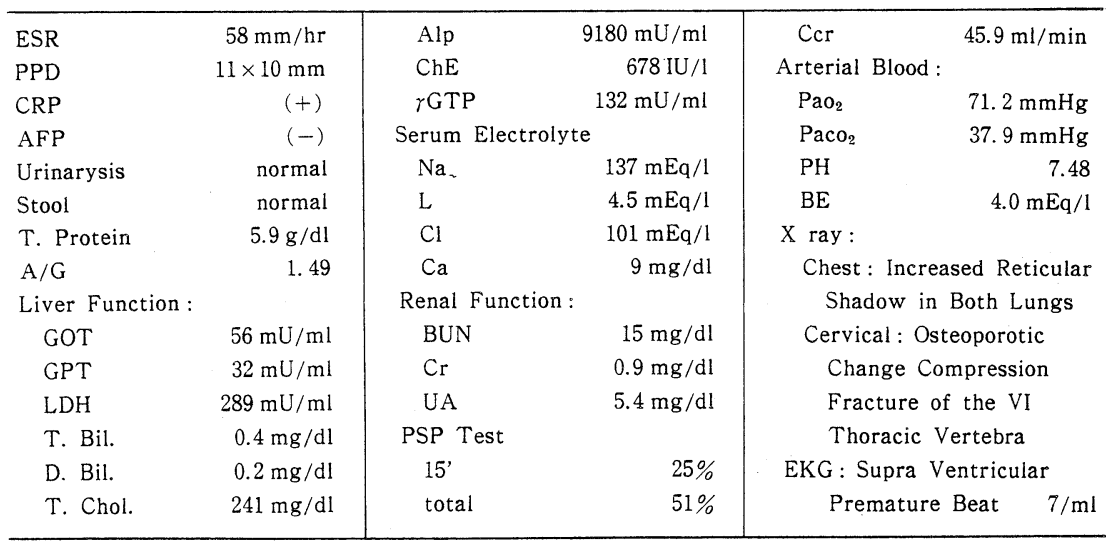

was worsened progressively and bone marrow puncture which was done several times disclosed "dy tap".

Physical findings on admission included a pulse rate of $96 / \mathrm{min}$ with irregular beat, anemia at palpebral conjunctiva and slightly enlarged anterior and posterior cervical lymph nodes with with tenderness. There was no definite hepatosplenomegaly. Initial laboratory data included moderate elevation of blood sedimentation rate, mild degree of hypoproteinemia and abnormalities of liver and renal chemistries (Table 1). Serum alkalinephosphatase value was 9,180 $\mathrm{mU} / \mathrm{ml}$. X-ray films of the chest revealed infiltrates suggestive of interstitial shadow in bilateral lower lung areas. The VIIth thoracic vertebra was subjective to flattening and compression fracture. Moderate degree of anemia was observed, while WBC count was within normal range with a few immature myelocyte and relative lymphocytosis

Table 2. Hematological Findings on Admission

\begin{tabular}{|c|c|c|c|}
\hline \multicolumn{2}{|c|}{ Peripheral Blood } & \multirow{2}{*}{\multicolumn{2}{|c|}{$\begin{array}{l}\text { Bone Marrow Biopsy: } \\
\text { Marked Fibrous Proliferation }\end{array}$}} \\
\hline $\mathrm{RBC}$ & $261.0 \times 14^{4} / \mathrm{mm}^{2}$ & & \\
\hline $\mathrm{Hb}$ & $8.6 \mathrm{~g} / \mathrm{dl}$ & \multirow{2}{*}{\multicolumn{2}{|c|}{ In. Vitro Culture of Bone }} \\
\hline $\mathrm{Pl}$ & $13.8 \times 14^{4} / \mu 1$ & & \\
\hline Ret & $16.0 \%$ & CFU-C & $41 / 2 \times 10^{5} \mathrm{MNCs}$ \\
\hline WBC & $6,900 / \mathrm{mm}^{2}$ & \multirow{2}{*}{\multicolumn{2}{|c|}{$\begin{array}{l}\text { CFU-E } \quad 1 / 1 \times 10^{5} \mathrm{MNCs} \\
(\text { Epo } 1.0 \mathrm{U} / \mathrm{ml})\end{array}$}} \\
\hline Stab & $19 \%$ & & \\
\hline Seg & $24 \%$ & (BFU-E & $12.5 / 1 \times 10^{5} \mathrm{MNCs}$ \\
\hline Eos & $3 \%$ & \multicolumn{2}{|c|}{ Lysozyme: } \\
\hline Ly & $43 \%$ & Serum & $21.8 \mu \mathrm{g} / \mathrm{ml}$ \\
\hline Mo & $4 \%$ & Urine & $326.0 \mu \mathrm{g} / \mathrm{ml}$ \\
\hline Promyelo & $1 \%$ & $\mathrm{sFe}$ & $131 \mu \mathrm{g} / \mathrm{dl}$ \\
\hline Myelo & $4 \%$ & TIBC & $286 \mu \mathrm{g} / \mathrm{dl}$ \\
\hline \multicolumn{2}{|c|}{$\begin{array}{l}\text { Bone Marrow Aspiration: } \\
\text { Dry Tap }\end{array}$} & $\begin{array}{l}\text { sFDP } \\
\text { sFbg }\end{array}$ & $\begin{array}{r}16 \mu \mathrm{g} / \mathrm{dl} \\
128 \mathrm{mg} / \mathrm{dl}\end{array}$ \\
\hline
\end{tabular}

in leukocyte differential count (Table 2). Bone marrow biopsy specimen from iliac bone revealed marked fibrous proliferation. A count of CFUc, CFUe and BFUe in vitro culture of peripheral blood was within the normal range. LZM levels in serum and urine was high showing 21.8 and $326.0 \mu \mathrm{g} / \mathrm{ml}$, respectively.

The patient's clinical course is shown in Fig. 1.

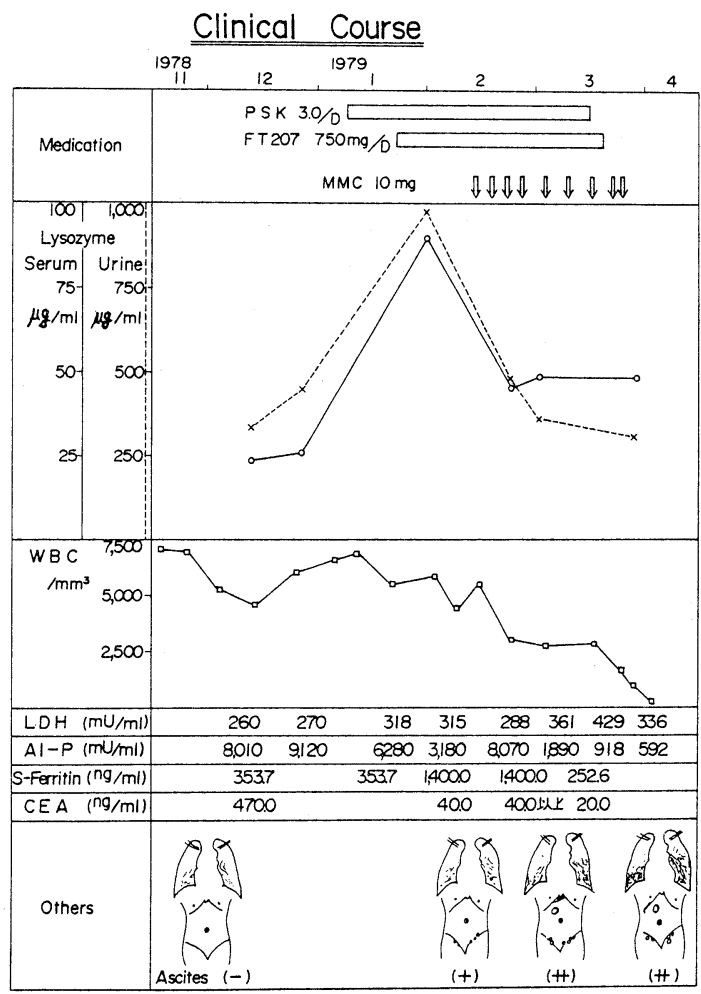

Fig. 1. 
In the X-ray-films of the whole bones, mixed osteolytic and osteoplastic changes were observed, concomitant with marked elevation of erythrocyte sedimentation rate and serum CEA levels (Table 3).

Study by gastrofiber-scope clarified the presence of gastric cancer at the body along the lesser curvature (macroscopically, Borrmann IV type). ${ }^{67} \mathrm{Ga}$ tumor scintigram revealed increased uptake of radioisotope to the whole bones such as vertebrae, 'ribs, pelvis, humerus. The 2 nd bone marrow biopsy 2 months after admission also disclosed remarkable fibrous proliferation and furthermore evident infiltration of large-sized atypical nucleated cells (partly with small sized glandular formation) was observed. Thus, the patient had secondary myelofibrosis due to disseminated bone marrow metastasis of gastric cancer. Liver and spleen scintigram with ${ }^{198} \mathrm{Au}$ did not disclose any abnormal findings.

Serial measurements of serum and urinary LZM always showed considerablly high levels, as serum LZM, was ranging from 20 to $90 \mu \mathrm{g} / \mathrm{ml}$ and urinary LZM from 300 to $1,000 \mu \mathrm{g} / \mathrm{ml}$. But

Table 3. Other Findings

\begin{tabular}{|c|c|c|}
\hline$\alpha \mathrm{FP}$ & $(-)$ & $X$ ray \\
\hline CEA & $470.0 \mathrm{ng} / \mathrm{ml}$ & Stomach: Gastric Cancer \\
\hline s Ferritin & $353.7 \mathrm{pg} / \mathrm{dl}$ & Advanced Borrman IV Type \\
\hline $\mathrm{C}_{3}\left(\beta_{1} \mathrm{C} / \beta_{1} \mathrm{~A}\right)$ & $86.0 \mathrm{mg} / \mathrm{dl}$ & Poorly Differentiated Adenocarcinoma \\
\hline $\mathrm{C}_{4}$ & $29.6 \mathrm{mg} / \mathrm{dl}$ & Colon: Normal Figure \\
\hline sIG $G$ & $530 \mathrm{mg} / \mathrm{dl}$ & Liver \& Spleen Scintigram: Normal \\
\hline IG A & $178 \mathrm{mg} / \mathrm{dl}$ & ${ }^{67} \mathrm{Ga}$-tumor Scintigram : Increased \\
\hline IG $M$ & $89 \mathrm{mg} / \mathrm{dl}$ & $\begin{array}{l}\text { Uptake of }{ }^{67} \mathrm{Ga} \text { In Vertebra, Clavicle, } \\
\text { Rib, Pelvis, Femur And Skull }\end{array}$ \\
\hline
\end{tabular}

throughout the whole clinical course, evident leukocytosis and monocytosis were not observed, while renal function was not severely disturbed. Furthermore, the serum ferritin and CEA indicated consistently high value, showing the former $250-1,400 \mathrm{ng} / \mathrm{ml}$, and the latter over $40 \mathrm{ng} / \mathrm{ml}$. And the trend of their rises and decreases was almost concomitant with the LZM levels in serum and urine (Fig. 1).

About one and half month after admission, the patient's status was gradually aggravated and in the middle of February in 1980, carcinomatous pleurisy and peritonitis with a large quantity of bloody pleural and peritoneal effusion were accompanied. High levels of LZM in ascites was also demonstrated, ranging from 70 to $85 \mu \mathrm{g} / \mathrm{ml}$. The patient died on June 7, 1981, complicated with sepsis and cachexia. Autopsy findings revealed advanced gastric cancer, macroscopically Borrmann IV type which primarily originated from gastric body along lesser curvature. Together with direct infiltration to parapancreato-retroperitoneal areas, carcinomatous peritonitis (bloody ascites up to $2,150 \mathrm{ml}$ ), carcinomatous pleurisy (bloody pleural effusion up to $1,150 \mathrm{ml}$ ) and extensive metastasis to the bone marrow, both lungs and systemic lymph nodes were observed. Carcinoma was poorly differentiated adenocarcinoma with relatively unclear glandular formation. A greater majority of secreting fluid in their glands and secretory granules within carcinoma cells were positively stained by PAS and alcian-

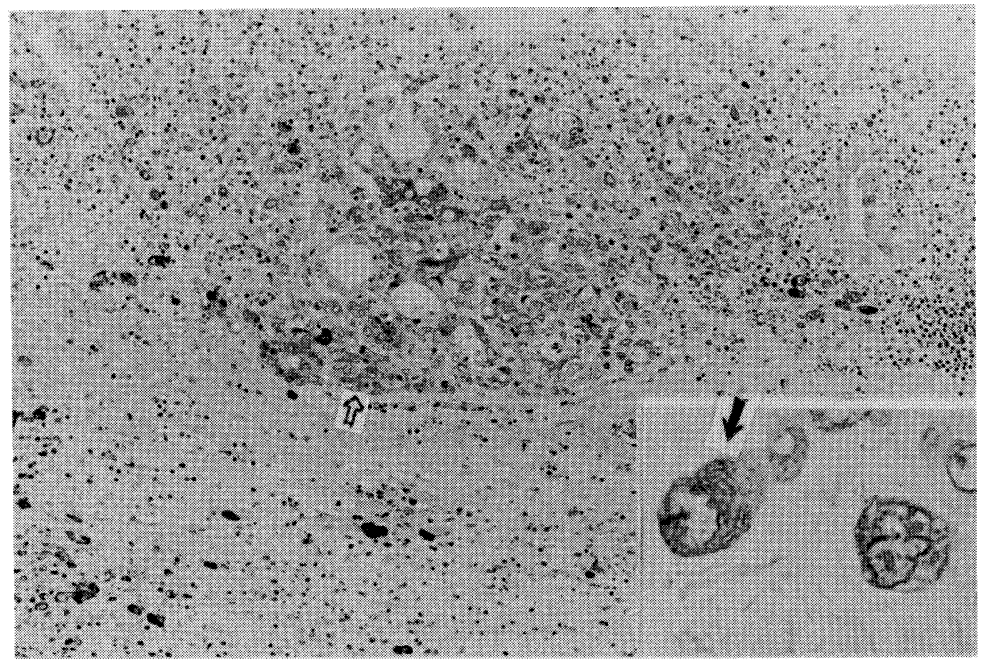

Fig. 2. Lysozyme positive findings of gastric carcinoma cells in both mucosa and submucosal layers. (PAP methods, posthematoxylin staining, $\times 40)$.

$\rightarrow$ Lysozyme positive carcinoma cell layer.

High magnification of lysozyme containing carcinoma cells (lower right, $x 1,000)$.

$\rightarrow$ Lysozyme positive carcinoma cells. 
blue staining. The presence of LZM within carcinoma cells was confirmed with the technique of peroxidase-antiperoxidase (PAP) (Fig. 2).

Extensive secondary myelofibrosis accompanied with cancer metastasis to bone marrow and markedly decreased intramedullary haemopoiesis were recognized (Fig. 3).

Mild to moderate degree of hemosiderosis was observed in the bone marrow, spleen $(65 \mathrm{~g})$ and the liver $(1,260 \mathrm{~g})$, whereas extramedullary haemopoiesis was not. Other findings revealed necrotic cholecystitis with abscess formation and systemic candidiasis (present in stomach, kidney, suprarenal gland, liver, lungs and brain).

\section{DISCUSSION}

This is a case who showed the markedly elevated LZM levels in serum and urine with advanced gastric carcinoma, histologically poorly differentiated adenocarcinoma complicated with secondary myelofibrosis due to metastasis to bone marrow. Serial measurements of the serum and urinary LZM always demonstrated high levels of them, whereas neutrophilia and/or monocytosis were not observed and kidney was not severely disturbed throughout the course. Therefore, what was the main cause of high levels of LZM in serum and urine in the patient was the major subject

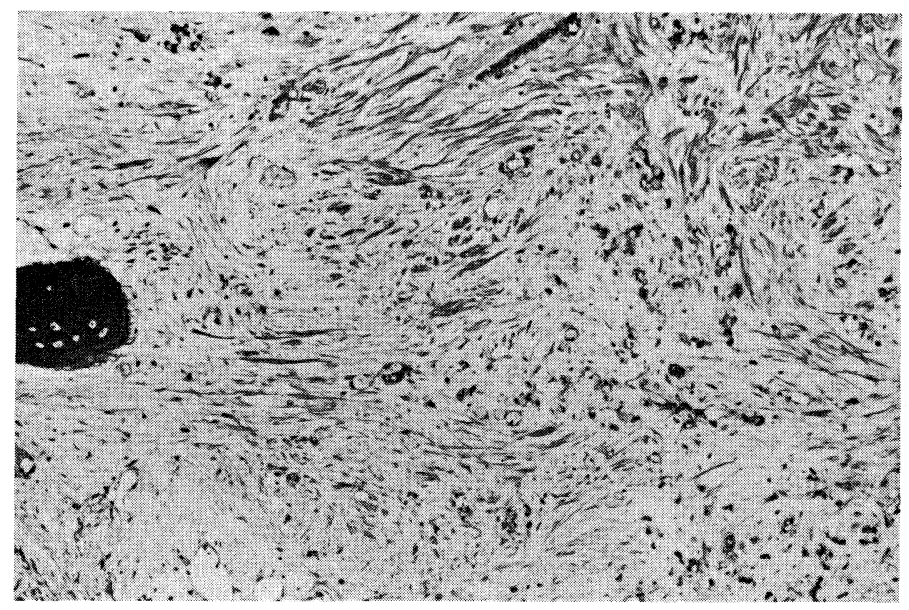

Fig. 3. Secondary myelofibrosis followed by bone marrow metastasis of gastric cancer.

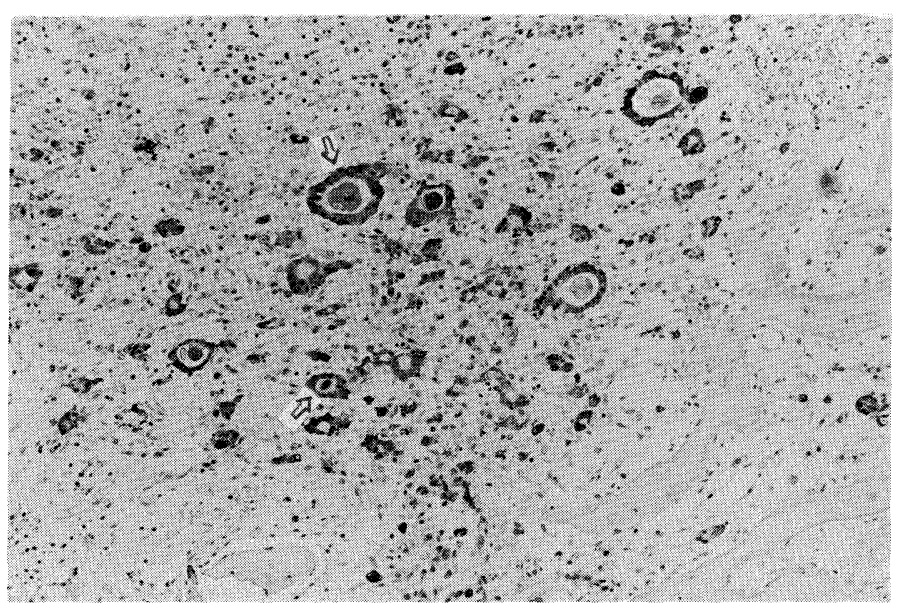

Fig. 4. Lysozyme positive findings at bone marrow metastatic sites. $\rightarrow$ Lsozyme postive areas. 
which shoule be clarified.

LZM staining by PAP techniques clarified the presence of LZM in tumor cells which did not derive from monocytes, neutrophils and Panethcells surrounding the tumor tissues.

It is considered, therefore, that gastric carcinoma cells secreted LZM and produced markedly elevated levels of LZM in serum and urine: this was a case possessing the characteristics of LZM secreting tumor. It is the known evidence that LZM is present in the homogenates of normal gastric mucosa, especially condensely at gastric fundus or pyloric regions through the biochemical research of normal gastric mucosa. ${ }^{27,28)}$

In vitro culture study with normal human gastrointestinal mucosa shed light on the fact that LZM might be only a little synthesized in such conditions, ${ }^{29)}$ whereas there were no reports as to whether LZM might be synthesized even in vitro culture with malignant transformed gastric mucosal cells or not. In general, the elevated LZM levels in serum and urine are verified in a variety of disorders as follows: (1) renal damage, (2) increased neutrophil and monocyte number and/or turnover rate, (3) some granulomatous diseases (sarcoidosis, tuberculoma, lepra, crohn's disease etc.), (4) increased functional capacities of neutrophils and/or monocytes, (5) some malignant tumors (AMoL, AMMoL, Paneth cell tumor, et al.). So, these disorders should be always taken into consideration in cases of the elevated levels of LZM in serum and/or urine. Hansen ${ }^{12)}$ menyioned that the kidney played a principal role of LZM handling in man. That is to say, LZM is a low molecular weight protein which can be easily filtrated through renal glomerulus and greater majority of it is reabsorbed at renal proximal tubules, without significant excretion into urine. In the process of reabsorption, a great deal of LZM accumulated in the kidney is hydrolized and destroyed at the lysosomes of proximal renal tubules. ${ }^{14,19)}$ The same phenomenon is observed in rat. ${ }^{13,15)}$ When blood urea level was over 20 $\mathrm{mg} / \mathrm{dl}$ and $30 \mathrm{mg} / \mathrm{dl}$, increased serum LZM levels (maximum $60 \mu \mathrm{g} / \mathrm{ml}$ ) was observed at the frequency of $74 \%$ and $90 \%$.

In this case, renal function is not severely disturbed. And hypo-potassemia, which is often ac- companied with elevated urinary LZM level, ${ }^{9,}$ 16) is not present. Therefore, it is hard to assess that renal damage was the major cause of the elevated levels in serum and urine. A concept of increased turnover rate of granulocyte and monocyte may be hard to take into account because peripheral WBC count and percent rate of neutrophil and monocyte were constantly within the range of $7,000 / \mathrm{mm}^{3}, 50 \%$ and $4 \%$, respectively.

Now, a little more attention concerning the influence of immunopotentiators "such as a BCG, OK432 and so on, should be paid carefully. In fact, it is said that alveolarmacrophages activated by BCG produce LZM three times as much as normal ones. ${ }^{18)}$ To be sure, krestine (PSK) - one of immunopotentiators - were administrated in this case, but it is difficult to interpret that the main cause of the markedly elevated levels of LZM in serum and urine was ascribed to PSK. Even if that agent had some stimulating effects to monocyte-macrophage series, the elevated levels of LZM in serum and urine had been already verified before administration of PSK.

As myelofibrosis (MF) was prominent in the patient, some correlations between myelofibrosis and LZM should be studied. But the serum and urinary LZM of some patients with myelofibrosis in the study of our clinic except for this case were ranging from normal to slightly high levels (Table 4). That is, the markedkly elevated serum and urinary LZM were not demonstrated in cases with $\mathrm{MF}$, different from this case.

In the past a few years, there were reports that the presence of LZM in gastric carcinoma tissues by using PAP techniques was observed. ${ }^{21,22)}$ But, among them, examinations were not done as to

Table 4. Myelofibrosis (MF) and Lysozyme (LZM)

\begin{tabular}{clcc}
\hline No. of cases & Disease & $\begin{array}{c}\text { Serum LZM } \\
(\mu \mathrm{g} / \mathrm{ml})\end{array}$ & $\begin{array}{c}\text { Urinary LZM } \\
(\mu \mathrm{g} / \mathrm{ml})\end{array}$ \\
\hline 1 & MF & 8.8 & 0.7 \\
2 & MF & 11.6 & 5.6 \\
3 & MF & 4.8 & 0.0 \\
4 & MF & 8.6 & 0.1 \\
5 & MF & 12.4 & 1.6 \\
6 & MF & 119.8 & 0.0 \\
7 & Secandary MF (AMgL) & 11.7 & 21.8 \\
8 & Secandary MF (CML) & 3.8 & 0.3 \\
9 & Secandary MF (CML) & 10.2 & 0.0 \\
\hline
\end{tabular}

AMgL: Acute Megakaryoblastic Leukemia CML: Chronic Myelogenouse Leukemia Diseases in the parenthesis denotes the underlying ones. 
how much LZM was secreted from carcinoma tissues to peripheral blood and urine. A recent report ${ }^{20)}$ exists in which LZM is present in adenocarcinoma cells derived from intestinal Paneth cells, however, where there were not mentioned as to whether they secreted LZM and caused the elevated levels of LZM in serum and urine. In other various sorts of carcinoma (such as carcinoma of mammary gland, renal cell carcinoma, malignant melanoma etc.), there are some papers in which serum LZM showed high levels. ${ }^{23-26)}$ But it is unclear whether these carcinoma cell produced LZM as LZM secreting tumors or not, because in which identification of LZM secretion from carcinoma cells by LZM staining was not done. In general, above mentioned events have been believed to be outcomes of either the presence of macrophages surrounding the carcinoma tissues or the increased secreting function of monocyte-macrophage series which recognized tumor antigens in tumor bearing patients. ${ }^{23)}$ In recent years, reports to assert the evidence of the frequent presence of LZM even in gastric carcinoma cells have appeared. ${ }^{20,22)}$

A few remarks may be required to assert that tumor cells secret LZM. That is, it is necessary to recognize carefully that not only LZM is stained in tumor tissues by the LZM staining, but also LZM positive cells are not normal LZM-containing gastric cells and/or monocytes, granulocytes and Paneth cells in tumor tissues. In our observation, the presence of monocytosis and/or neutrophilia, was not observed. And it is apparent that in this case Paneth cells did not contribute to the LZM secretion so much because tumor tissues included only a few Paneth cells.

Here some significance of the elevated serum and urinary levels of LZM in contrast to the physiological action of LZM.

LZM is present in normal gastric gland and small intestine. ${ }^{27)}$ It is likely that the intestinal LZM is mainly produced by Paneth cells ${ }^{30)}$ and LZM alone cannot lyse other bacteria than gram positive saprophytes; while in the presence of IgA and complement, LZM can also lyse various pathogenic organisms by making its antibacterial spectrum spread and enhance. ${ }^{31,32)}$ It is considered that LZM forms complexes with many antimucopolysaccharides and is related to nonspecific host antibacterial defense system on the cell surface of gastrointestinal mucosa, together with local mucosal $\operatorname{IgA}$ which is included in Paneth cells etc. ${ }^{27)}$ And it is also assumed that LZM is related to destruction of gastrointestinal mucosa on the formation of gastrointestinal injurues and ulcer. ${ }^{27)}$ There is the evidence that activated macrophages have elevated interferon and lysozyme secretion and that LZM is present in tumor-associated macrophages. If LZM plays some roles in local immune system, the problem as to whether LZM presented in tumor tissues is involved with anti-inflammatory and anti-tumor actions or not remains unsolved. In fact, there appeared a recent report to support the evidence that LZM, at least partially by its positive charge, is capable of enhancing in vitro monocyte tumor cell cytotoxicity; its secretion in vivo may potentiate monocyte-tumor cell interactions. ${ }^{35)}$

Concerning the significance of the elevated levels of LZM in serum and urine in clinical diagnosis, it was often prone to be limitedly accepted to be AMoL or AMMoL, under the condition of the absence of renal damage. ${ }^{33,34)}$ But it should be noted that even some malignant diseases such as solid tumors except for those sorts of leukemia might rarely demonstrate high levels of LZM in serum and/or urine, as observed in this case.

Why the serum and urinary levels of LZM was considerably reduced in the patient's terminal stage?

Perhaps its phenomenon might be explained through the ideas of decreased productions and secretions from tumor cells because of breakdown and degeneration of tumor tissues themselves due to the administration of anticancer drugs. Throughout the patient's course, levels of the serum ferritin and CEA, were moving almost concomitantly with those of the serum and urinary LZM.

The evidence might reveal an outcome which reflected the degree of proliferative activities of tumor tissues.

We reported here a case of gastric carcinoma with LZM secreting functional capacities, demonstrating the markedly elevated levels of LZM in 
serum and urine.

\section{REFERENCES}

1) Mason DY and Taylor CR: The distribution of muramidase (lysozyme) in human tissues. J Clin Pathol 28: 124, 1975.

2) Klokars $M$ and Reitamo S: Tissue distribution of lysozyme in man. J Histochem Cytochem 29: 932, 1975.

3) Kokoshis PL and Di Luzio NR: Serum lysozyme: An index of macrophge function. J Reticuloendothel Soc 25: 85, 1979.

4) Osserman EF and Lawlor DP: Serum and urinary lysozyme (muramidase) in monocytic and monomyelocytic leukemia. J Exp Med 124: 921, 1966.

5) Asamer H, Schmalzl E, et al: Immunocytological demonstration of lysozyme (muramidase) in human leukemic cells. Brit J Haemat 20: 571, 1971.

6) Geradine SP and Jonathan WS: Profile of intracytoplasmic lysozyme in normal tissues, myeloproliferative disorders, hairly cell leukemia and other pathologic process. Am J Pathol 89: 351, 1977.

7) Mason DY: Intracellular lysozyme and lactoferrin in myeloproliferative disorders. J Clin Path 30: 541, 1977.

8) Wiernick $\mathrm{PH}$ and Serpick AA: Clinical significance of serum and urinary muramidase activity in leukemia and other hematologic malignancies. Am J Med 46: 330, 1969.

9) Shimizu M, Takabayashi Y, et al: Serum and urine lysozyme activity in various blood disorders and hypopotassemia in leukemia. Japan J Clin Hemat 13: $549,1972$.

10) Reitamo S, Klockars $M$, et al: Human lysozyme; Origin and distribution in health and disease. Ric Clin Lab 8: 211, 1978.

11) Reitamo S, Reitamo J, et al: The distribution of lysozyme in human gastric mucosa in inflammatory and neoplastic disorders. Acta Path Microbiol Scand Sect A 87: 451, 1979.

12) Hansen NE, Karle $H$, et al: Lysozyme turnover in man. J Clin Invest 51: 1146, 1979.

13) Klockars $M$ and Ossermon EF: Localization of lysozyme in normal rat tissues by an immunoperoxidase method. J Histochem Cytochem 22: 139, 1974.

14) Christensen EI and Manusbach AB: Intralysosomal digestion of lysozyme in renal proximal tubule cells. Kidney Int 6: 396, 1974.

15) Glynn AA and Parkmen R: Studies with antibody to rat lysozyme. Immunology 7: 724, 1964.

16) Prockop DJ and Davidson EW: A study of urinary and serum lysozyme in patient in monocytic and myelomonocytic leukemia with renal disease. New Engl J Med 270: 1, 269, 1964.

17) Cohn AZW and Wiener E: The particulate hydrolases of macrophages. I. Comparative enzymology, isolation and properties. J Exp Med 118: 991, 1963.

18) Ouchi E, Sato $Y$, et al: The effect of immunopotentiator having influence on lympho-reticular systems's function (I). J Jap Soc Res 18: 121, 1978.

19) Muggia FM, Henneman HO, et al: Lysozymuria and renal tubular dysfunction. Am J Med 47: 351, 1969.

20) Reitamo SJ, Reitamo JY, et al: Lysozyme in neoplastic Paneth cells of a jejunal adenocarcinoma. Acta Path Microbiol Scand Sect A 89: 165, 1981.

21) Ifuzi $\mathrm{H}$, Shimamoto $\mathrm{F}$, et al: Cell differentiation in malignant tumor of digestive tract. J Jap Soc Cancer 265, 1980.

22) Tsutsumi $Y$ and Mikata A: Histochemical studies on mucin and secretory glycoproteins in early gastric carcinoma. Acta Histochem Cytochem 14: 82, 1981.

23) Kamakura M, Ohashi $T$, et al: The study concerning lysozyme. Lysozyme levels within monocytes in peripheral blood of cancer bearing patients. Acta Haematol Jpn 44: 144, 1981.

24) Miyajima $\mathrm{H}$ and Takeuchi $\mathrm{T}$ : Paneth cell tumor: An additional case of duodenal adenoma with malignant change. Beitr Pathol 157: 419, 1976.

25) Scharfenberg JC and Decamp PT: Neoplastic Paneth cells. Occurrence in an adenocarcinoma of a Meckel's deverticulum. Am J Clin Pathol 64: 204, 1975.

26) Stern JB and Sobel $\mathrm{HJ}$ : Jejunal carcinoma with cells resembling Paneth cells. Arch Pathol 72: 61, 1961.

27) Meyer K, Prudden JF, et al: Lysozyme content of the stomach and its possible relationship to peptic ulcer. Proc Soc Exp Biol Med 65: 220, 1947.

28) Meyer K, Prudden JF, et al: Lysozyme activity in ulcerative alimentary disease. I. Lysozyme in peptic ulcer. Am J Med 5: 487, 1948.

29) Lai A, Fat RFM, McClland DBL, et al: In vitro synthesis of immunoglobulin secretory components, complement and lysozyme by human gastrointestinal tissues. I. Normal tissues. Clin Exp Immuno 23: 9, 1976. II. Pathologic tissues. Clin Exp Immunol 23: 20, 1976.

30) Peters $T$ and Vantppen G: The Paneth cell: A source of intestinal lysozyme. Gut 16: 553, 1975.

31) Adinolfi M, Glynn AA, et al: Serological properties of $\mathrm{rA}$ antibodies to escherichia coli present in human colostrum. Immunology 10: 510, 1966.

32) Hill IR and Porter P: Studies of bacteriocidal activity to escherichia coli of porcine serum and colostral immunoglobulins and the role of lysozyme with secretory IgA. Immunology 26: 1236, 1974.

33) Linman JW: Myelomonocytic leukemia and its preleukemic phase. J Chronic Dis 22: 713, 1970.

34) Terada H: Diagnosis of leukemia. The New Medical Care 6: 121, 1979 (in Japanese).

35) LeMarbre P, Rinehart JJ, et al: Lysozyme enhànces monocyte-mediated tumorcidal activity. Blood 58: 994, 1981. 